\title{
EXISTENCE THEOREMS OF GENERALIZED QUASI-VARIATIONAL INEQUALITIES WITH UPPER HEMI-CONTINUOUS AND DEMI OPERATORS ON NON-COMPACT SETS
}

\author{
MOHAMMAD S. R. CHOWDHURY ${ }^{1}$ AND ENAYET TARAFDAR
}

Abstract. Suppose that $E$ is a topological vector space and $X$ is a non-empty subset of $E$. Let $S: X \rightarrow 2^{X}$ and $T: X \rightarrow 2^{E^{*}}$ be two maps. Then the generalized quasi-variational inequality problem $(\mathrm{GQVI})$ is to find a point $\hat{y} \in S(\hat{y})$ and a point $\hat{w} \in T(\hat{y})$ such that $\operatorname{Re}\langle\hat{w}, \hat{y}-x\rangle \leqslant 0$ for all $x \in S(\hat{y})$. We shall use Chowdhury and Tan's generalized version [4] of Ky Fan's minimax inequality [7] as a tool to obtain some general theorems on solutions of the GQVI in locally convex Hausdorff topological vector spaces. We obtain the existence theorems of GQVI on paracompact sets $X$ where the set-valued operators $T$ are demi operators [3] and are upper hemi-continuous [5] along line segments in $X$ to the weak * -topology on $E^{*}$.

Mathematics subject classification (1991): 47H04, 47H05, 47H09, 47H10, 49J35, 49J40, 54C60.

Key words and phrases: Generalized quasi-variational inequality, $h$-demi operators, demi operators, lower semi-continuous, upper semi-continuous and upper hemi-continuous operators.

\section{REFERENCES}

[1] J. P. Aubin, "Applied Functional Analysis", Wiley-Interscience, New York, 1979.

[2] D. Chan AND J. S. PANG, The generalized quasi-variational inequality problem, Math. Oper. Res. 7 (1982), 211-222.

[3] M. S. R. ChOWDHuRY, Generalized variational inequalities for upper hemi-continuous and demi operators with applications to fixed point theorems in Hilbert spaces, Serdica Math. J. 24 (1998), 163-178.

[4] M. S. R. ChOwdhuRY AND K.-K. TAN, Generalization of Ky Fan's minimax inequality with applications to generalized variational inequalities for pseudo-monotone operators and fixed point theorems, J. Math. Anal. Appl. 204 (1996), 910-929.

[5] M. S. R. CHOWDHURY AND K.-K. TAN, Generalized variational inequalities for quasi-monotone operators and applications, Bulletin of the Polish Academy of Sciences 45, No. 1 (1997), 25-54.

[6] J. DugundJI, Topology, Allyn abd Bacon, Inc., Boston, 1966.

[7] K. FAN, A minimax inequality and applications, in "Inequalities", Vol. III, "Proceedings, Third Symposium on Inequalities"(O. Shisha, Ed.), Academic Press, New York, pp. 103-113, 1972.

[8] H. KNESER, Sur un thèorème fondamental de la thèorie des jeux, C. R. Acad. Sci. Paris 234 (1952), 2418-2420.

[9] R. T. Rockafeller, Convex Analysis, Princeton University Press, Princeton, 1970.

[10] M.-H. SHIH AND K.-K. TAN, Generalized quasi-variational inequalities in locally convex topological vector spaces, J. Math. Anal. Appl. 108 (1985), 333-343.

[11] M.-H. SHIH AND K.-K. TAN, Generalized bi-quasi-variational inequalities, Journal of Mathematical Analysis and Applications 143 (1989), 66-85.

[12] W. TAKAHASHI, Nonlinear variational inequalities and fixed point theorems, Journal of the Mathematical Society of Japan 28 (1976), 168-181. 